\title{
O ENFOQUE CULTURAL E O INSTITUCIONAL NO PATRIMO- NIALISMO DE HOLANDA E FAORO
}

THE CULTURAL AND INSTITUTIONAL APPROACH IN THE PATRIMONIALISM OF HOLANDA AND FAORO

\section{Fábio Hoffmann', Lucas José Naibert Gelinski²}

RECEBIDO: 17/04/2019 | ACEITO: 27/06/2019

DOI: $10.5902 / 2317175837761$

\section{RESUMO}

O objetivo do presente texto é descrever e caracterizar os principais pontos referentes ao patrimonialismo nas obras os Donos do Poder e Raízes do Brasil de Raymundo Faoro e Sérgio Buarque de Holanda, respectivamente. Tal caracterização revela que o enfoque utilizado por Faoro, em Os Donos do Poder, tem relação com concepção institucional, uma vez que sua análise se detém ao desenho das instituições que permeiam o poder, enquanto que em Raízes do Brasil, de Holanda, estão amarradas a um recorte de cunho culturalista, onde se pode buscar, no modelo civilizatório português, a genética da sociedade brasileira. 0 método utilizado é descritivo explicativo, valendo-se não só das obras destes dois pensadores, mas também alguns de seus comentaristas. Considerações preliminares revelam que os dois enfoques não só se complementam para a análise da realidade do Brasil contemporâneo, mas que também em muitos casos são indissociáveis.

Palavras-chave: Patrimonialismo; Estamento; Sérgio Buarque de Holanda; Raymundo Faoro.

\footnotetext{
1 Mestre em Ciência Política pela Universidade Federal de Pelotas (UFPEL), tem especialização em Marketing, Direito Eleitoral e Partidário pelo Centro Universitário Internacional (UNINTER), e é bacharel em Ciência Política pela Universidade Luterana do Brasil (ULBRA). É pesquisador associado ao Centro Latino-Americano de Estudos em Cultura (CLAEC), e filiado à Asociación Latinoamericana de Ciencia Política (ALACIP) e à Associação Brasileira de Ciência Política (ABCP).

2 Mestre em Desenvolvimento Rural pela UFRGS (2017): Cientista Politico pela Universidade Luterana do Brasil (2014). Licenciado em História pelo Centro Universitário Leonardo Da Vinci (2013).
} 
O ENFOQUE CULTURAL E O INSTITUCIONAL NO PATRIMONIALISMO DE HOLANDA E FAORO

\section{ABSTRACT}

The aim of the present text is to describe and characterize the main points referring to patrimonialism in the works the Owners of Power and Roots of Brazil by Raymundo Faoro and Sérgio Buarque de Holanda. Such a characterization reveals that Faoro's approach in The Owners of Power is related to an institutional conception, since its analysis stops at the design of institutions that permeate power, whereas in Raizes do Brasil, in the Netherlands, they are tied to a culturalist cut, where one can look for in the Portuguese civilization model the genetics of Brazilian society. The method used is explanatory descriptive, using not only the works of these two thinkers, but also some of its commentators. Preliminary considerations reveal that the two approaches not only complement each other for the analysis of the reality of contemporary Brazil, but also in many cases are inseparable.

Keywords: Patrimonialism; Stratum; Sérgio Buarque de Holanda; Raymundo Faoro.

\section{Introdução}

A busca pelo conhecimento envolve um ambiente que, segundo Weber (2006), prepare o espírito para absorção e a elaboração de problemas científicos e os desenvolvam a partir de uma metodologia bem delineada e raciocínio originais. Sérgio Buarque de Holanda e Raymundo Faoro não só desenvolveram seus espíritos para entenderem o Brasil como também se valeram do método compreensivo e pluricausal, além dos próprios conceitos weberianos de poder e patrimonialismo. Todavia, para Holanda, em sua tese do homem cordial, a noção de patrimonialismo permeia todo o social, imiscuindo nas relações sociais, confundindo o público com o privado, procurando penetrar nas brechas da burocracia e driblar a normatividade. Para Faoro, esta lógica fica restrita ao Estado e suas instituições; é nelas que o estamento se vale para perpetuar sua lógica de dominação. O metacampo formando pelo Estado na análise bourdieusiana (2014) é o "metaclasses" faoriano formado pelo estamento acima de todas as outras classes.

O objetivo deste artigo é caracterizar o enfoque cultural e o institucional nas abordagens de interpretação do Brasil de Sérgio Buarque de Holanda e Raymundo Faoro. Tal caracterização é importante para a clarividência conceitual usada pelos autores, bem como o recorte de ir buscar na gênese do coIonizador (Estado e sociedade portuguesa), elementos que expliquem o Brasil. A validade dos enfoques cultural e institucional para a análise da realidade brasileira a partir do conceito de patrimonialismo permanecem fortes, principalmente para um país onde a corrupção endêmica e sistêmica faz convergir teses onde o ponto comum é a permanente indiferenciação entre o público e o privado, o usufruto do primeiro em benefício do segundo, tanto na sociedade, quanto no Estado.

O artigo está estruturado da seguinte forma: além desta breve introdução, abordamos o conceito de dominação patrimonial e estamento em Max Weber; em seguida passamos a tratar da escrita e seus autores, a questão da cordialidade em Sérgio Buarque de Holanda, sua metodologia dos contrários, 
a imutabilidade das instituições em Raymundo Faoro, o controle patrimonialista do Estado e a sociedade patrimonial $\mathrm{x}$ a sociedade de mercado; reforçamos o enfoque dado nas duas interpretações sobre o Brasil (cultural e institucional); e por fim, as considerações finais reforçam a atualidade da obra destes dois pensadores.

\title{
20 conceito de dominação patrimonial e estamento
}

Os conceitos de patrimonialismo e estamento são de suma importância dentro do pensamento construído por Max Weber (2004). Para entender esses dois termos é necessário ter em mente a concepção de sociedade como um conjunto formado por instâncias (econômica, política, jurídica, religiosa etc.) que inter-relacionam, mas que são também independentes umas das outras. Nesse sentido, um tipo de dominação tradicional exercido por uma casta ou estamento em determinada sociedade independe de seus recursos econômicos, mas depende da dominação embasada na tradição.

Weber desenvolve o conceito de patrimonialismo como resultado da dominação patriarcal tradicional, onde o peso do status social e da força conservada na tradição ultrapassa o campo econômico dentro da esfera privada da sociedade. Mas ao longo de sua obra, conforme vai atentando para a estruturação das modernas burocracias e as novas formas de fazer política através da democracia, Weber evolui e adéqua seu conceito de patrimonialismo como característica de algumas forças ou grupos políticos que tendem ao domínio do Estado,

\begin{abstract}
dos princípios estruturais pré-burocráticos é o mais importante a estrutura patriarcal da dominação. Em sua essência, não se baseia no dever de servir a determinada "finalidade" objetiva e impessoal e na obediência a normas abstratas, senão precisamente no contrário: em relações de piedade rigorosamente pessoais. Seu germe encontra-se na autoridade do chefe da comunidade doméstica. (WEBER, 2004, p. 234).
\end{abstract}

Conforme aponta Bruhns, (2012, p. 66), pode-se observar uma evolução no conceito de patrimonialismo de Weber que, "não fala mais de uma versão patriarcal do patrimonialismo. Ele opera uma distinção entre (i) o patriarcalismo primário, princípio estrutural relacionado ao lar e (ii) o patrimonialismo enquanto forma de dominação política". É exatamente nesse segundo sentido (sentido moderno) do termo patrimonialismo, usado enquanto dominação dos aparelhos estatais, que vai acontecer toda a construção lógica e metodológica de Os Donos do Poder:

ao cargo patrimonial falta, sobretudo a distinção burocrática entre a esfera "privada" e a "oficial". Pois também a administração política é tratada como assunto puramente pessoal do senhor, e a propriedade e o exercício de seu poder político, como parte 
O ENFOQUE CULTURAL E O INSTITUCIONAL NO PATRIMONIALISMO DE HOLANDA E FAORO

integrante de seu patrimônio pessoal, aproveitável em forma de tributos e emolumentos. (WEBER, 2004, p. 253).

Dentro dessa lógica de dominação patrimonial apresentada por Weber, na qual o chefe e seus patrícios faltam com a distinção do privado e do público, não se pode deixar de enxergar a sociedade e suas divisões. Nesse sentido, o termo estamento acaba se colocando como uma categoria muito importante para a análise do patrimonialismo no pensamento de Raymundo Faoro $(1979,2000)$, pois esse termo, ao lado do conceito de patrimonialismo, forma dois conceitoschave que percorrem todo o enredo de Os Donos do Poder, do começo ao fim.

A separação entre classe, estamento e partidos na obra de Weber é fundamental, pois a posição de barganha perante o mercado é um atributo essencial para a classe, mas não para o estamento que é legitimado pelo status social. "Pertencer a uma determinada classe não implica em possuir qualquer sentimento de comunidade ou consciência de interesses ou direitos. Isso acontece tipicamente com os membros do estamento" (QUINTANEIRO et al., 2003, p. 116). A sensação de pertencimento vai ser um dos elementos fundamentais do estamento weberiano. É ao se sentir como parte integrante do grupo que acaba originando os privilégios a esse grupo. $O$ estamento está para além da classe, seus membros podem pertencer a diferentes classes sociais, a posição do estamento está embasada em valores não econômicos, mas em valores morais, institucionalizados pela sociedade.

os estamentos, em contraste com as classes, são, em regra, comunidades, ainda que frequentemente de natureza amorfa. Em oposição à "situação de classe", determinada por fatores puramente econômicos, compreendemos por 'situação estamental' aquele componente típico do destino vital humano que está condicionado por uma específica avaliação social, positiva ou negativa, da honra, vinculada a determinada qualidade comum a muitas pessoas. (WEBER, 2004, p. 180).

A classificação do Estado Brasileiro, segundo uma ótica weberiana através dos conceitos de estamento e patrimonialismo, está presente na obra de Faoro (op. cit.), mas se tem em Raízes do Brasil de Sérgio Buarque de Holanda, (também tributária do pensamento de Weber) o uso do patrimonialismo para uma análise da cultura da sociedade brasileira para além dos círculos estatais.

\section{A escrita e seus autores}

Raízes do Brasil de Sérgio Buarque de Holanda se constitui como uma das obras seminais do pensamento político brasileiro. Ao lado de Gilberto Freyre, o autor se tornou um da geração dos anos 1930 que contemporaneamente chamamos de intérpretes do Brasil, numa das décadas mais importantes da consolidação do Brasil republicano, e do Brasil enquanto nação em um 
mundo onde o neocolonialismo reinava junto às teses acadêmicas de eugenia. O Brasil procurava um significado para si e um lugar no mapa político do globo enquanto nação republicana e independente.

A influência weberiana recebida por Sérgio Buarque em sua formação intelectual fica exposta de maneira clara em Raízes do Brasil: ao tratar da burocracia como um tipo ideal e sua incompatibilidade com o corpo técnico do Estado Brasileiro, bem como da dominação carismática do homem cordial, ou do patriarcalismo que sai do mundo rural e se transforma em patrimonialismo no Brasil moderno e urbano, está se falando sob uma linguagem tipicamente weberiana, presente principalmente em Economia e Sociedade e no ethos de A Ética Protestante e o Espírito do Capitalismo.

Uma história de cunho cultural, embasada em terminologias weberianas, é o que atribui sentido a Raízes do Brasil. Assim a obra se distingue das visões pessimistas embasadas em fatores biológicos, como Oliveira Vianna (1956), quanto da democracia racial de Gilberto Freyre (2003). Raízes do Brasil pode ser concebido como um estudo capaz de absorver a lógica da ação social, no sentido weberiano do termo, através de uma busca histórica nas características gerais da sociedade e não somente no estamento de poder, ou na simples ideia de etnias. "[...] o método utilizado por Sérgio Buarque é genético e weberiano: busca a gênese, as raízes do processo histórico a ser analisado e intenta enquadrar esse processo em uma tipologia weberiana, de cuja utilização ele é pioneiro entre nós" (SOUZA, 2007, p. 343). A escolha da sociologia weberiana por Holanda como seu norte teórico da construção de seu estudo histórico de cunho cultural teve como objetivo entender as mazelas do Brasil, assim como a classificação dos agentes da ação social sob um viés metodológico de comparação dos contrários, o aproximando da dialética Hegeliana, reflexos de sua passagem pela Alemanha em 1929.

A criação de tipos ideais que transcendem o tempo e o espaço e tem suas raízes no modelo de colonização e exploração português, que de uma maneira ou de outra, influenciam sempre a contemporaneidade, são uma marca na escrita de Holanda. $\mathrm{O}$ arquétipo de tipo ideal é o próprio homem cordial de Holanda, o qual, escapando nas brechas das leis e convenções, consegue tirar proveito pessoal das situações. O tipo ideal do homem cordial pode ser caracterizado contemporaneamente pelo "jeitinho brasileiro" (DAMATTA, 1997). A presença de uma dialética aberta, sem síntese, apenas com tese e antítese, faz da construção geral de Raízes do Brasil não apenas um olhar para as raízes, mas também para o presente e o futuro.

Já Os Donos do Poder de Raymundo Faoro que, assim como Raízes do Brasil, recebeu importante influência do pensamento de Weber, faz parte de outra geração de intérpretes do Brasil, esta da década de 1950. Ao lado de autores como Antonio Candido e Celso Furtado, Raymundo Faoro se torna destaque através da obra Os Donos do Poder (op. cit.) com uma análise inovadora da sociedade brasileira sob o olhar da ciência política, o que tornava sua 
O ENFOQUE CULTURAL E O INSTITUCIONAL NO PATRIMONIALISMO DE HOLANDA E FAORO

interpretação singular quando comparada não só a dos autores de sua geração, mas também com a geração anterior a essa. Assim como Sérgio Buarque Holanda, Raymundo Faoro também era formado em ciências jurídicas, além disso, a utilização do arcabouço teórico weberiano, para a explicação histórica da realidade brasileira é outra aproximação entre ambos os autores.

Em entrevista concedida em 2002 a Santos Junior (2009), Faoro explica que foi o acaso que o fez entrar em contato com a obra de Max Weber, em 1944, pois ninguém indicara o autor; "Eu tomei conhecimento por esse acaso. E pela leitura que eu fiz nesse tempo, que me parecia dar a chave para muitas coisas do Brasil. Talvez nenhum autor tivesse me sugerido tanto como o Weber" (SANTOS JÚNIOR, 2009, p. 98). O conceito de estamento que vai se tornar um dos termos mais relevantes da obra de Raymundo Faoro remete diretamente à Weber, deste modo, para Faoro, o estamento burocrático através do Estado é que vai formar a sociedade brasileira, e não o contrário. Essa lógica do Estado anterior à sociedade é bem distinta da concepção de Sérgio Buarque, onde é a sociedade rural, marcada pelo patriarcalismo é que vai dominar o Estado e, até em certo sentido, moldá-lo. Para Faoro, a questão central para o Brasil é o Estado Português, enquanto que para Holanda é a colonização portuguesa no sentido geral do que o termo colonização agrega, para além do Estado.

Uma visão de mundo marcada pela crítica às escolas marxistas, e um olhar simpático para a concepção de sociedade liberal, são uma herança da sociologia de Weber, que vai permear à concepção de mundo escolhida para escrever Os Donos do Poder. Um primeiro apoio ao Golpe Civil-Militar de 1964, ou ao que se chamou de revolução na época, e mais tarde uma postura contrária aos governos militares no final da década de 1970 na condição de presidente da Ordem dos Advogados do Brasil (OAB), são marcas que revelam o ideário político de Raymundo Faoro, e sua posição com relação à um Estado que não pode ser inimigo da liberdade. Essa visão de mundo crítica em relação ao modelo de Estado formado ou implantado no Brasil é parte integral da formulação de Os Donos Do Poder e de toda a obra do autor que vai para além de seus escritos.

\subsection{Raízes do Brasil e a cordialidade na sociedade brasileira}

O brasileiro cordial na obra de Sérgio Buarque de Holanda é um dos elementos fundamentais para sua compreensão de Brasil. Longe de ser uma obra estritamente historiográfica que apenas busca tratar do passado como simples fato histórico, Raízes do Brasil, busca na história a compreensão do presente através da constituição do ethos brasileiro. Holanda cria um tipo ideal de brasileiro patrimonialista, fruto da herança portuguesa; um homem cordial, que mescla ingenuidade com oportunismo, racionalidade com emoção, polos contrários que se ajustam através das situações cotidianas. Nesse sentido, a boa e calorosa "recepção" brasileira, além de ser um elemento composto por 
naturalidade, está imbricada em um tipo de racionalidade para a conquista de seu interlocutor. Nesse sentido o brasileiro através de seu comportamento "bonzinho" vai contornando as práticas burocráticas, através do jeitinho brasileiro calcado no individualismo, avesso à hierarquia, e "armado dessa máscara o indivíduo consegue manter sua supremacia ante o social" (HOLANDA, 1995, p. 147). Percebe-se o caráter individualista do homem cordial onde o indivíduo se sobrepõe às convenções sociais constituídas em regras e hierarquias. Contornar as regras estabelecidas socialmente, descaracterizar a impessoalidade das leis e da burocracia que constitui a democracia. É deste modo que o homem cordial de Holanda contorna os caminhos da sociedade de tipo racional legal, através de sua "cordialidade".

Há nesse sentido uma incompatibilidade entre a ideia de homem cordial e ação coletiva organizada para interesses gerais. Segundo Holanda os traços mais presentes na comunicação do "homem cordial" é a ausência de sobrenomes e o tratamento direto pelo primeiro nome, bem como o emprego do diminutivo "inho" em pessoas e coisas denotando o caráter de sentimentalismo e relação de familiaridade. $O$ brasileiro cordial é a pura manifestação do patrimonialismo, do interesse privado sobrepondo a coisa pública. A cordialidade brasileira é resultado da colonização ibérica conjugada à conjuntura histórica do Brasil rural, escravocrata e indígena, onde as relações sociais sempre se deram através da pessoalidade e da ausência de ritos. Esse ambiente civilizador foi o responsável por construir um ethos de brasilidade apoiado em valores que reverenciam o personalismo nas relações sociais que vão do universo privado até as relações do universo público.

O homem cordial brasileiro não é o patrimonialista circunscrito ao estamento burocrático. Não é em razão de seu cargo ou função que o homem cordial é personalista e avesso à impessoalidade, como seria o membro do estamento burocrático de Faoro, mas em razão de seu próprio ethos constitutivo. $\mathrm{O}$ homem cordial é incompatível com normatização democrática. Para Holanda o problema do patrimonialismo na sociedade brasileira não está nas instituições formais lotadas por um estamento de poder, mas na cultura: "assim, a ausência de verdadeiros partidos não é entre nós, como há quem suponha singelamente, a causa de nossa inadaptação a um regime legitimamente democrático, mas antes um sintoma dessa inadaptação" (HOLANDA, 1995, p. 183).

O homem cordial para Sergio Buarque é fruto do meio rural e seu patriarcalismo, onde "o quadro familiar torna-se, assim, tão poderoso e exigente, que sua sombra persegue os indivíduos mesmo fora do recinto doméstico. A entidade privada neles precede sempre, a entidade pública" (HOLANDA, 1995, p. 82). O homem cordial de Sérgio Buarque é o resultado histórico dos séculos de formação da sociedade brasileira, do que o autor chama de raízes do Brasil. 


\subsection{Metodologia dos contrários}

O antagonista do tipo ideal de homem cordial, que pensa com os sentimentos e em si próprio, tentando passar por cima das regras da impessoalidade, pode ser o tipo de homem racional legal, que usa uma racionalidade embasada na polidez e nas regras formais ou informais de bom senso para resolver seus problemas. É claro que nenhum dos dois tipos, são tipos puros ou perfeitos na realidade social. "No que nos distinguimos dos ingleses, por exemplo, que não tendo uma constituição escrita, regendo-se por um sistema de leis confuso e anacrônico, revelam, contudo, uma capacidade de disciplina espontânea sem rival em nenhum outro povo", argumenta Holanda (1995, p. 178). Para o autor no Brasil as leis não passam de mero formalismo, pois a pessoalidade e a indisciplina as tornam quase inúteis.

Uma dialética de contrários é uma constante na obra de Holanda, como se fossem modelos históricos em choque, mas sem solução presente. E será que a solução ou síntese dessa dialética estaria aberta no futuro? Holanda argumenta que uma superação da doutrina democrática só será efetivamente possível, entre nós, quando tenha sido vencida a antítese liberalismo-caudilhismo.

De maneira geral a utilização de pares antagônicos vai revelando uma proposta para o futuro do Brasil, pois a obra não é carregada de elementos que possam constituir uma imutabilidade institucional ou cultural, como no estamento patrimonial de Faoro. Sendo que os pares revelam modelos históricos em choque em uma sociedade em mudança, em "revolução" como diz o próprio Holanda.

\subsection{Os Donos do Poder e imutabilidade das instituições}

O esforço de construir uma obra calcada na análise da estruturação do poder político no Brasil e suas influências para a formação da nação brasileira acaba fazendo da obra de Faoro, uma construção típica da ciência política por ter o poder como centro do estudo. Todavia, para uma obra desta envergadura, o autor recorre a um aprofundado recorte histórico anterior a colonização portuguesa do Brasil.

A origem do Estado Português é o primeiro capítulo da obra de Faoro, publicada inicialmente em 1958. É notável que quase nenhuma menção é feita neste capítulo sobre os hábitos ou relações de classe deste povo no determinado período histórico que começa a partir do século XI. Mas é dedicada uma atenção especial sobre a divisão do poder e as investidas bélicas desse Estado nascente. No primeiro capítulo fica claro o esforço do autor de mostrar o patrimonialismo e a indistinção dos negócios privados do rei com os negócios da coroa, e a importância do comércio enquanto categoria econômica importante sobrepujando a elite da terra, e que "a estrutura patrimonial levará, porém, à estabilização da economia, embora com maior flexibilidade do que o feudalismo" (FAORO, 1979, p. 21). 
Para Faoro, a construção de um império comercial, que acabou retardando o processo de revolução industrial associado às dinâmicas internas, fez de Portugal um reino não feudal, uma espécie de negócio; o capitalismo politicamente orientado, assentado na figura do príncipe e seu corpo administrativo. Dentro dessa lógica, a nascente burguesia atuava apenas através da concessão do rei, o auge da consolidação da monarquia portuguesa vai ocorrer através da construção desse capitalismo politicamente orientado que vai culminar na revolução da dinastia de Avis (1385 - 1580), na qual vão se chocar os interesses da nascente burguesia com os interesses da elite agrária, pelo controle do Estado. A vitória da burguesia vai fazer de Portugal um Estado centralizado precocemente, obrigando-o a recorrer ao comércio e descobertas ultra-marítimas.

Esse longínquo passado ibérico, melhor dizendo da formação do Estado Ibérico, vai ser de suma importância ao longo da obra de Faoro. Esse estágio inicial da formação do Estado Português vai deixar rastros de sua genética no decorrer da construção dos modelos políticos brasileiros. O negócio do rei ou do príncipe vai se tornar o negócio do estamento burocrático, e "a cultura, que poderia ser brasileira, frustra-se ao abraço sufocante da carapaça administrativa, trazidas pelas caravelas de Tomé de Souza [...]" (FAORO, 2000, p. 363).

Apesar da falta de clareza no que diz respeito sobre a caracterização do que seria realmente o estamento burocrático dentro das instituições brasileiras, o termo é de suma importância para compreender a falta de mudanças na sociedade brasileira e a perenidade das instituições e onipotência do Estado. $\mathrm{Na}$ verdade, não se pode confundir a classe política com estamento burocrático, não que essas duas categorias não se mesclem, pois uma pode permear a outra sem ser a mesma coisa, mas que "do antigo Portugal a nossos dias, no entender do autor, cabe ao estamento burocrático a direção dos negócios, o papel decisivo; como o Estado é o centro de tudo, esse grupo é o principal" (IGLESIAS, 2009, p. 49).

O recorte histórico feito por Faoro da formação do Estado Português até o estado novo de Vargas revela que seu foco não é avaliar o patrimonialismo fora do âmbito do poder como fez Sérgio Buarque de Holanda, mas sim dentro das esferas que tendem ao domínio do Estado. Nesse sentido, podemos arriscar a dizer que seu ponto de vista não é culturalista, mas institucionalista, o que está em jogo na obra de Faoro não são os fatores que envolvem a vida privada dos indivíduos e seus hábitos, mas a relação de controle do mundo político, e "a clivagem primordial dá-se entre estamento burocrático e o restante da sociedade, incluindo-se nesse 'resto' as camadas proprietárias ou não" (CAMPANTE, 2003, p. 154).

Dessa forma, Faoro não se preocupa em caracterizar os agentes fora do estamento burocrático em divisão de classes, mas apenas em como a sociedade tem interesses dissociado dos interesses do estamento burocrático. Nesse sentido, não se entende que o patrimonialismo seja uma categoria válida para todo o conjunto da sociedade, mas apenas para o estamento. Essa é uma das 
diferenças mais importantes com relação ao patrimonialismo de Sérgio Buarque de Holanda, que agrega as relações privadas através da cordialidade e da impessoalidade dos brasileiros. Já a impessoalidade em Faoro aparece com a relação dos membros do estamento com a burguesia associada, não se percebe um patrimonialismo nas relações fora do âmbito do Estado.

Mas a imutabilidade das instituições brasileiras, ou o que o autor chama de "viagem redonda" no capítulo final dos Donos do Poder, acaba colocando como o papel da sociedade. Um dos motivos para isso talvez fosse que o patrimonialismo de Estado é um modelo que automaticamente exclui a cidadania, onde o "Estado e nação, governo e povo, dissociados e em velado antagonismo, marcham em trilhas próprias, num equívoco renovado todos os séculos, em contínua e ardente procura recíproca" (FAORO, 1979, p. 94).

Da revolução Avis e o congelamento do estamento burocrático, passando pela chegada deste ao Brasil através das caravelas portuguesas, se tem o desfecho do sonho idílico da nova terra: "como curso do tempo, a imagem do paraíso se esvairá, perdida, com a assimilação do novo mundo pelo velho, na embriaguez mercantil." (FAORO, 1979, p.103). Essa dominação do novo mundo pelo velho mundo estamental português, embasado em um mercantilismo exploratório vai ser o ponto inicial de formação da sociedade brasileira, e acoplamento do estamento burocrático dentro das novas circunstâncias. Acoplamento esse que se renova de tempos e tempos na visão de Faoro.

\subsection{O controle patrimonialista do Estado}

A apropriação do Estado por um estamento que é aberto, ou seja, pode ser permeado de baixo para cima independente dos fatores econômicos, é a marca da dominação política no Brasil. Para Faoro sempre a classe dirigente é, de certo modo, uma face do estamento patrimonialista, que faz dos negócios públicos seu empreendimento pessoal. Dessa maneira há um desprezo pela distinção público/privado. Essa indistinção das coisas do rei e do reino não é tão somente de caráter material, mas também dos elementos simbólicos capazes de gerar poder ao cargo, que acaba se personalizando no indivíduo.

As atividades econômicas, os interesses, os contratos não se reduzem, dentro desse contexto social, ao ganho, ao lucro e às vantagens materiais. Tudo se subordina à glória, à honra, ao incremento dos valores que o estamento corporifica, atolado na cobiça, mas com a cabeça nas nuvens (FAORO, 1979, p. 67).

Esse controle patrimonialista sobre o Estado se dá através dos órgãos institucionalizados como o exército, judiciário, burocracia de tipo patrimonialista, pessoal e não racional legal, e também da própria classe política que, ascendendo ao poder, começa a jogar as regras do jogo do estamento. 
3.5 A sociedade patrimonial versus a sociedade de mercado

O estamento governa e cabe a uma burguesia, associada ao estamento mediante à concessões, realizar os negócios. Não é o mercado que comanda a dinâmica econômica, mas o estamento com seus interesses voltados para si. Desde os negócios da coroa até os governos populistas, Faoro acaba enxergando o Estado como o grande gestor da economia. Na visão do autor, o político acaba se sobressaindo ao econômico.

Nessa lógica o estamento burocrático de corte patrimonialista acaba se tornando um empecilho para o desenvolvimento do capitalismo. Pode-se dizer que na "cosmovisão" de Faoro, a necessidade de um capitalismo não orientado, mas livre nas dinâmicas de mercado seria o ideal para o desenvolvimento das sociedades. Essa visão de mundo o insere como um clássico liberal. $O$ estado patrimonial acaba retendo a atividade econômica ao seu entorno, deixando toda uma classe burguesa retida ao Estado.

A falta de classificação da sociedade fora do estamento, e as duras críticas feitas à elite na obra, não deixam claro de onde surgiria e se desenvolveria o capitalismo no Brasil, se não pela orientação do Estado. Mas de fato, a realidade tem mostrado que partidos políticos e organizações que chegam ao poder com o objetivo de derrubar o estamento burocrático, acabam se tornando parte dele. As empreiteiras e os casos de corrupção, o abuso de poder por parte de juízes, e pessoalidade dos burocratas no Brasil contemporâneo, são marcas da persistência do estamento na sociedade brasileira.

\section{Duas interpretações sobre o Brasil}

Tanto Sérgio Buarque de Holanda como Raymundo Faoro, são dois pioneiros na utilização dos aportes teóricos de Max Weber para interpretar o Brasil. A utilização explícita dos conceitos de dominação e poder, ou implícita dos tipos ideais e do ethos enquanto influência na vida econômica e social da sociedade brasileira é uma realidade nas duas obras, no entanto, o termo que mais chama à atenção em ambas as obras, principalmente por sua presença constante, é o patrimonialismo. Conforme apontamos no início do texto, o patrimonialismo weberiano é uma forma de dominação assentada na tradição. Embora o termo guarde o mesmo sentido para os dois intérpretes do Brasil: apropriação privada do público, devido a indistinção desses dois espaços, pessoalidade nas relações de poder e burocráticas. Os lugares de manifestação e tendência histórica são diferenciados nos dois autores e suas respectivas obras.

Sendo assim, o patrimonialismo retratado em os Donos do Poder é um patrimonialismo que ocorre nos altos escalões do poder, um patrimonialismo que coopta quem chega ao poder, pois é o código de conduta do grupo que detém a burocracia e o poder, ou o que Faoro usando a linguagem weberiana denomina de estamento. Mas de fato Faoro jamais chega a chamar a socieda- 
O ENFOQUE CULTURAL E O INSTITUCIONAL NO PATRIMONIALISMO DE HOLANDA E FAORO

de brasileira de patrimonial ou qualquer um dos elementos que esse conceito pode agregar de pessoalidade e ausência de regras gerais, apenas critica o estamento e de certo modo as elites do país por aceitarem e até mesmo tirarem proveito da dominação patrimonial feita pelo estamento através do Estado. Tanto é fato isso, que Faoro era um dos críticos centrais das ideias de Celso Furtado acerca do papel do Estado no fomento da economia.

Então, a visão de Faoro sobre o patrimonialismo é institucional e não cultural. Pois o problema não se encontra nos traços gerais da civilização brasileira, mas no lócus do poder. O recorte de Faoro é a partir das instituições formais do Estado, centro do poder da classe dirigente. Os interesses da sociedade são completamente contrários aos interesses do estamento ou do Estado que o personaliza. Mas Faoro não deixa claro o interesse da sociedade, nem mesmo como algum tipo de representatividade pode solucionar esse problema. Pelo contrário, parece haver uma anomia na sociedade que assiste bestializada ao drama político da nação. $O$ estamento parece ser para o autor à própria regra do jogo, pois ele molda classes e ideologias ao seu gosto. Aqueles que chegam ao poder jogam de acordo com as regras do estamento. Há assim um patrimonialismo para a manutenção do poder e a construção de uma riqueza particular, e uso legítimo de bens ilegítimos perante a lei.

Já o patrimonialismo em Sérgio Buarque de Holanda é um patrimonialismo que está nas raízes do processo civilizatório do Brasil, no passado colonizador, no ethos da sociedade brasileira e não só em um estamento do poder. É do aventureiro, desbravador individual, que em busca de riqueza desbrava o território do futuro Brasil, que vai nascer o modelo ideal de homem cordial, avesso às regras e que tudo reduz aos padrões pessoais e afetivos. Sérgio Buarque de Holanda também fala do patrimonialismo dentro dos órgãos burocráticos do Estado: "não era fácil aos detentores das posições públicas de responsabilidade, formados por tal ambiente, compreenderem a distinção fundamental entre os domínios públicos e privados" (HOLANDA, 1995, p. 145). Mas para o autor isso não era um problema institucional do Estado ou de algum estamento, mas sim fruto da cultura, ou do ambiente como diz o autor. Não há um estamento patrimonial fechado em si, mas uma sociedade patrimonial aberta à mudança através de uma dialética que pode ser traduzida em modelos históricos.

A maioria dos escritos enquadrados no arcabouço conceitual de uma interpretação do Brasil - embora possa ser de variados campos, como economia, sociologia, história, etc. — são, na verdade, análises do presente baseadas no passado sem que se deixe de tomar as devidas perspectivas para o futuro. Desse modo, Raízes do Brasil e Os Donos do Poder são obras dotadas de um passado, presente e futuro. Para os dois autores mais que uma economia forte, o que interessava era o futuro do país e de um possível regime democrático.

Embora Os Donos do Poder pareça ter herdado certo pessimismo maquiavélico, quanto às relações de poder, seu autor lutava pelo estabelecimento da democracia e da revogação dos atos institucionais da ditadura militar e a 
consequente reintrodução do habeas corpus na legislação brasileira. Além de ter contribuído para a ideia de criação de um partido fora do establishment do estamento, ou seja, de um partido que se originasse da sociedade e não do Estado. Esse engajamento pessoal, todavia, não aparece - ao menos de maneira explícita - nos Donos do Poder, que lega certo niilismo com relação à construção democrática no Brasil. Desde o primeiro capítulo da obra, até a síntese de conclusão intitulada "a viagem redonda", Os Donos do Poder parece indicar o que se chama na visão institucionalista de path dependence.

O path dependence (dependência de trajetória) é um caminho que se auto-reforça, e que faz com que as matrizes institucionais persistam mesmo em cenários de mudança. Desde a consolidação do império português ultramarino até o Estado desenvolvimentista de Vargas, o que Faoro enxerga é uma matriz institucional imutável que persiste ao tempo e a modernização do mundo, portanto, onde "o enigma nacional é o da irredutibilidade de uma condição que não apenas se prende ao passado, mas o reproduz, como um pesadelo que nos captura e asfixia" (FAORO, 2000, p. 388). Já o vislumbre de uma sociedade democrática e de um futuro melhor é uma realidade em Raízes do Brasil que, diferente de Os Donos do Poder, não vê apenas um peso no passado português. Tanto que para Holanda, não havia povo mais adequado para o processo civilizatório do Brasil do que o português. Apesar deste modelo implementado pelos portugueses ter sido o responsável também pelas características negativas da sociedade brasileira, a grande novidade em Sérgio Buarque de Holanda é que esse passado é passível de ser transformado:

ainda testemunhamos presentemente, e por certo continuaremos a testemunhar durante largo tempo, as ressonâncias últimas do lento cataclismo, cujo sentido parece ser o do aniquilamento das raízes ibéricas de nossa cultura para a inauguração de um estilo novo, que crismamos talvez ilusoriamente de americano, porque seus traços se acentuam com maior rapidez em nosso hemisfério. [...] No dia em que o mundo rural se achou desagregado e começou a ceder rapidamente à invasão impiedosa do mundo das cidades, entrou também a decair, para um e outro, todo o ciclo das influencias ultramarinas especificas de que foram portadores os portugueses (HOLANDA, 1995, p. 172).

Gilberto Freyre (op. cit) atenta em Casa Grande e Senzala para o fato das reais possibilidades de uma democracia racial no Brasil, enquanto Sérgio Buarque de Holanda desloca esse eixo para as relações de classe, pois ele afirma que pela desventura as classes cultas estão apartadas do resto da nação e não por culpa própria. Nesse sentido, Holanda consegue enxergar uma trajetória com possíveis mudanças através de modificações dessas relações sociais, fruto do passado rural e patriarcal legados pela colonização portuguesa. 


\section{Conclusões}

Há, sem dúvida, atualidade tanto na obra de Raymundo Faoro quanto na de Sérgio Buarque de Holanda no que diz respeito ao Brasil do século XXI. Quando se observa a supremacia do poder judiciário perante as decisões políticas, bem como o abuso de poder dos membros dessa classe, que conseguem fazer com que as leis não se apliquem a eles próprios, estamos vendo o próprio estamento burocrático de Faoro persistindo no tempo e no espaço.

Também a classe política, independente da origem do partido tem revelado sua capacidade regenerativa patrimonial, gerenciadora de um capitalismo orientado, como se vê através da relação entre lideranças políticas e partidos com empresas, tanto estatais como no caso da Petrobrás e o Banco Nacional de Desenvolvimento Econômico e Social (BNDES), quanto privadas (Odebrecht, Grupo Camargo Correa e Grupo OAS). Tudo isso concorre para demonstrar a persistência do lócus institucional, mesmo em meio a processos de mudanças.

A cordialidade aparente do povo brasileiro, a impessoalidade, ou o não funcionamento das leis escritas que são contornadas pela pessoalidade e pela arbitrariedade dos sentimentos, revelam os traços de uma sociedade que não completou sua evolução política para uma burocracia racional-legal weberiana. Assim, tais características que poderiam ser contornadas ou aproveitadas de maneira positiva permanecem sendo deletérias para o desenvolvimento da sociedade brasileira. O olhar culturalista que Sérgio Buarque de Holanda estendeu para analisar a história do Brasil permanece ainda muito atual e importante para a compreensão do Brasil contemporâneo.

Novos estudos devem investigar o impacto das relações oriundas da lógica patrimonial para a capacidade do Estado brasileiro. Se a prática desta lógica está imbricadamente ligada à uma cultura do patrimonialismo, como abordado ao longo do texto, é natural que tais dinâmicas de navegação social e sobrevivência do estamento afetem diretamente o sentimento de pertencimento e, mais ainda, as regras assumidas pela sociedade e pelo Estado enquanto motores da evolução sociopolítica brasileira. É o dilema da viajem redonda que ainda persiste no Brasil.

O artigo está bem articulado ao que se propõem e cumpre com as condições para ser publicado. Há, todavia, que ser feita uma revisão na digitação, por haver alguns erros que atrapalham o bom nível do texto. Tem o trabalho avaliado bons méritos como leituras da Sociologia clássica brasileira e pode ser de boa contribuição para pesquisadores interessados no tema. 


\section{Referências}

BRUHNS, Hinnerk. O conceito de patrimonialismo e suas interpretações contemporâneas. Estudos Políticos, n. 4, p. 61-77, 2012. CAMPANTE, Rubens Goyatá. O patrimonialismo em Faoro e Weber e a sociologia brasileira. Dados - Revista de Ciências Sociais, v. 46, n.1, p. 153-193, 2003.

DAMATTA, Roberto. Carnavais, malandros e heróis: para uma sociologia do dilema brasileiro. Rio de Janeiro: Rocco, 1997. FAORO, Raymundo. Os donos do poder: formação do patronato político brasileiro. Vol. 1. Porto Alegre: Globo, 1979.

Os donos do poder: formação do patronato político brasileiro. Vol.2. Rio de Janeiro: Globo, 2000.

HOLANDA, Sérgio Buarque de. Raízes do Brasil. São Paulo: Companhia das Letras, 1995.

IGLESIAS, Francisco. Revisão de Raymundo Faoro. In: GUIMARÃES, Juarez. (org.). Raymundo Faoro e o Brasil. São Paulo: Perseu Abramo, 2009.

QUINTANEIRO, Tania. Um toque dos clássicos: Marx, Durkheim e Weber. Belo Horizonte: UFMG, 2003.

SANTOS JÚNIOR, Jair dos. Entrevista com Raymundo Faoro: uma viagem ao universo intelectual do autor. In: GUIMARÃES, Juarez (org.). Raymundo Faoro e o Brasil. São Paulo: Perseu Abramo, 2009.

SOUZA, Ricardo Luiz de. As raízes do Brasil e o futuro do "homem cordial" segundo Sérgio Buarque de Holanda. Caderno CRH, Salvador, v.20, n.50, p.343-353, 2007.

VIANA, Oliveira. A evolução do povo brasileiro. Ed. José Olympio: Rio de Janeiro, 1956.

WEBER, Max. Economia e sociedade: Fundamentos da sociologia compreensiva. Vol. 2. São Paulo: Universidade de Brasília, 2004.

Ciência e política: duas vocações. São Paulo: Martin Claret, 2006. 